\title{
Efeito da temperatura e da solução conservante na qualidade pós-colheita de Zingiber spectabile Griff. ${ }^{(1)}$
}

\author{
JOSÉ LUIZ MOSCA(2); ROBSON ASSUNÇÃO CAVALCANTE(3); VLAYRTON TOMÉ MACIEL ${ }^{(4)}$ e \\ WALDELICE OLIVEIRA DE PAIVA(2)
}

\begin{abstract}
RESUMO
Hastes florais de sorvetão (Zingiber spectabile Griff.) foram colhidas no Câmpus Experimental da Embrapa Agroindústria Tropical, situada em Fortaleza (CE), no início da manhã, quando as inflorescências apresentavam 15 a $20 \mathrm{~cm}$ de comprimento. Após a colheita, as hastes florais foram levadas para o Laboratório de Fisiologia e Tecnologia Pós-colheita e submetidas ao processo de limpeza, imersas por 30 segundos em solução fúngica e, posteriormente, submergidas em água para retirada do excesso de solução. Procedeu-se ao corte basal das hastes florais (padronizado em $40 \mathrm{~cm}$ ) e à hidratação por período de uma hora. Após o período de hidratação, as hastes florais foram condicionadas aos tratamentos de armazenamento refrigerado nas temperaturas de $13^{\circ} \mathrm{C}$ ou $15^{\circ} \mathrm{C}$ e associação com condicionamento em solução comercial Flower ${ }^{\circledR}(30 \mathrm{~mL}$ do produto por $1 \mathrm{~L}$ de água) ou em água. Avaliaram-se a cada dois dias o percentual de massa fresca e a aparência visual mediante escala subjetiva de notas. Não houve diferenças significativas entre os tratamentos no parâmetro aparência visual, permanecendo com qualidade até o $16^{\circ}$ dia após a colheita. Quanto ao percentual de massa fresca, não houve interação entre os fatores soluções e temperatura, tendo apresentado efeitos significativos, isoladamente, as hastes florais armazenadas em temperatura de $13^{\circ} \mathrm{C}$; as hastes armazenadas em solução conservante comercial apresentaram maiores médias do que as armazenadas a $15^{\circ} \mathrm{C}$ e em água, respectivamente.
\end{abstract}

Palavras-chave: Zingiber spectabile Griff., solução conservante, temperatura.

ABSTRACT

Temperature and maintenance solution effects on postharvest quality of Zingiber spectabile Griff.

Floral stems of gingiber (Zingiber spectabile Griff.) were harvested at the Embrapa Tropical Agroindustry Experimental Campus, located in Fortaleza, state of Ceará, in the first hours of the morning, when the inflorescences presented from 15 to $20 \mathrm{~cm}$ of length. After the harvest the floral stems were lead for the Laboratory of Physiology and Postharvest Technology to the experimental unit, being submitted to the cleaning process, immersed for 30 seconds in solution fungicide and later submerged in water for withdrawal of the excess of fungicide solution. Soon was proceeded the basal cut of the steams (standardizing to $40 \mathrm{~cm}$ ) and watering for period of one hour. The floral steams had been conditional to the treatments of cold storage in $13^{\circ} \mathrm{C}$ or $15^{\circ} \mathrm{C}$ and UR $85 \%$ associated with storage in commercial maintenance solution Flower $(30 \mathrm{~mL}$ of the product for $1 \mathrm{~L}$ of water) or in water. Every two days the fresh mass percentage and visual appearance were evaluated by means of subjective note scale. The treatments did not show significant differences on visual appearance remaining with quality for $16^{\circ}$ day the harvest. Relating to fresh mass percentage, it did not have interaction between the factors separately solutions and temperature, having presented significant effect, with the floral steam stored in temperature of $13^{\circ} \mathrm{C}$ and the stored in commercial maintenance solution presented bigger averages of that stored $15^{\circ} \mathrm{C}$ and water, respectively. Key words: Zingiber spectabile Griff., maintenance solution , temperature.

\section{INTRODUÇÃO}

A floricultura, em sentido amplo, abrange o cultivo de flores e plantas ornamentais com produtos, destacando-se em diversos fins e formas de apresentação, que podem ser comercializados como flores de corte e plantas envasadas, floríferas ou não, sementes, rizomas, bulbos e mudas de árvores e outras formas de propágulos (CASTRO, 1998).
LOPES (2001) apontou para tendência de saturação do mercado mundial de plantas ornamentais tradicionalmente utilizadas, o que representava oportunidade de incremento na produção e comercialização de novas espécies. Dentre os países que poderiam se beneficiar com esse fato, o Brasil, possuidor de uma flora bastante diversificada, apresenta enorme potencial para a produção e fornecimento de flores e plantas ornamentais, assim como material propagativo,

\footnotetext{
(1) Trabalho recebido para publicação em 03/08/2006 e aprovado em 23/07/2008.

(2) Embrapa Agroindústria Tropical, Caixa Postal 3761, 60511-110 Fortaleza (CE). mosca@cnpat.embrapa.br

(3) Universidade Federal do Ceará. Bolsista PIBIC/CNPq. agrobson@gmail.com

(4) Engenheiro Agrônomo. Bolsista CNPq. Embrapa Agroindústria Tropical.
} 
típicas de clima tropical ou temperado.

As exportações dos produtos da floricultura brasileira atingiram em 2007 um incremento de 9,1\% em relação ao ano anterior (KIYUNA et al., 2008). O país registrou maior volume comercializado, US\$ 35,3 milhões, tendo como grande destaque o comércio de mudas (US\$ 15,3 milhões) seguidas de bulbos (US\$ 14 milhões). No mesmo trabalho, os autores atentam para o fato preocupante relativo à diminuição do volume exportado das flores de corte para buquês. Esse quadro pode ser revertido com a adoção de políticas de oferta de novos produtos ou produtos de melhor qualidade em relação aos já oferecidos nos países tradicionais compradores e naqueles de menor tradição.

Dentre os produtos da floricultura brasileira, muito comercializado como flor de corte para buquês, tipicamente de clima tropical, destaca-se o Zingiber spectabile Griff.. Conhecida popularmente como gengibre ornamental, cotonete de elefante, sorvetão, é uma planta herbácea, rizomatosa, perene, de brácteas de coloração amarelobrilhante a róseo-avermelhado sustentadas por haste ereta (LAMAS, 2002).

Como um típico produto vegetal, após a colheita, as flores de sorvetão sofrem alterações bioquímicas, fisiológicas e estruturais constituindo o processo de senescência, o qual está relacionado com a diminuição do teor de água, redução de reservas, aumento da produção e ação do etileno e redução da absorção de água (CHITARRA e CHITARRA, 1990).

A estocagem refrigerada é extremamente efetiva na redução da respiração, preservando os suprimentos de reservas e conseqüentemente prolongando a vida póscolheita do produto (OLIVEIRA, 1996). Segundo MORAES (1999), produtos de origem tropical não toleram temperaturas muito baixas podendo apresentar perdas da integridade da membrana e variações na atividade enzimática.

Outro tratamento, bastante difundido na cadeia produtiva de flores de corte, cujo principal objetivo é o de manter a qualidade durante a vida pós-colheita, é o uso de soluções conservantes, definidas como substâncias que apresentam em sua composição grande concentração de açúcares, ácidos orgânicos, inibidores de síntese ou ação do etileno, bactericidas (TAGLIACOZZO et al., 2005) e que podem ser aplicados durante todas as etapas da cadeia ou nos momentos iniciais após a colheita.

O objetivo deste trabalho foi avaliar o efeito de solução conservante comercial associada à refrigeração no prolongamento da vida pós-colheita de hastes florais de Zingiber spectabile Griff.

\section{MATERIAL E MÉTODOS}

Hastes florais de sorvetão (Zingiber spectabile Griff.), cultivadas em ambiente protegido por sombrite a $70 \%$, foram colhidas no início da manhã no Câmpus Experimental da Embrapa Agroindústria Tropical, situada em Fortaleza - Ceará. O ponto de colheita adotado foi o mesmo preconizado por LAMAS (2004), ou seja, hastes florais que apresentavam inflorescências de 15 a $20 \mathrm{~cm}$ de comprimento. Entende-se por hastes florais o conjunto formado por inflorescência e haste do pseudocaule.
Após a colheita as hastes florais foram levadas para o Laboratório de Fisiologia e Tecnologia PósColheita e submetidas ao processo de limpeza que consistiu na remoção de restos florais existentes entre as brácteas da inflorescência, na lavagem com água e sabão neutro com auxílio de esponja macia e, em seguida, na imersão por 30 segundos em solução fúngica, com posterior retirada do excesso da solução por meio de submersão em água. Logo após, procedeu-se ao corte basal das hastes florais padronizado em $40 \mathrm{~cm} \mathrm{(20} \mathrm{cm} \mathrm{da}$ inflorescência e $20 \mathrm{~cm}$ da haste do pseudocaule) e à hidratação delas por um período de uma hora à temperatura ambiente $\left(25^{\circ} \mathrm{C}\right)$ em recipientes com água proveniente da companhia de abastecimento da região.

Após o período de hidratação, as hastes florais foram condicionadas aos tratamentos de armazenamento refrigerado nas temperaturas de $13^{\circ} \mathrm{C}$ ou $15^{\circ} \mathrm{C}$ e UR $85 \%$ associadas com condicionamento em solução comercial Flower ${ }^{\circledR}(30 \mathrm{~mL}$ do produto por $1 \mathrm{~L}$ de água $)$ ou em água procedente da companhia de abastecimento, sendo renovadas a cada avaliação tanto a solução conservante quanto a água.

Realizaram-se avaliações visuais a cada dois dias até o momento do descarte, com base no acompanhamento da qualidade das hastes florais sob critério subjetivo de notas adaptado de CASTRO (1993):

0 - Haste e/ou inflorescência túrgida e de coloração característica.

1 - Início de amarelecimento e/ou murcha da haste.

2 - Amarelecimento e/ou murcha parcial da haste e/ou início de murcha das brácteas.

3 - Haste murcha e/ou amarela e murcha parcial das brácteas.

4 - Brácteas murchas e/ou quebra da base da inflorescência.

Para efeito de critérios, consideraram-se as inflorescências com nota média igual ou inferior a dois com qualidade comercial e, a partir da nota 3 , as hastes florais eram consideradas impróprias à comercialização e ao consumo.

No primeiro dia de avaliação, foram separadas três hastes florais de cada tratamento e determinada a massa fresca de cada uma delas. De dois em dois dias determinava-se a massa fresca das mesmas hastes e, com base no primeiro dia, o percentual da massa fresca até o momento do descarte.

$\mathrm{O}$ experimento foi realizado em delineamento inteiramente casualizado em esquema fatorial $2 \times 2$; o primeiro fator referiu-se às temperaturas refrigeradas $(13 \mathrm{e}$ $15^{\circ} \mathrm{C}$ ) e o segundo, às soluções de manutenção (água e solução comercial Flower( ${ }^{\circledR}$ ).

Os dados foram submetidos à análise de variância com a utilização do software SISVAR versão 4.03 e, caso houvesse efeito significativo, determinava-se a curva de regressão das médias.

\section{RESULTADOS E DISCUSSÃO}

Considerada como principal característica de avaliação das flores, a aparência externa está diretamente relacionada com o potencial de comercialização do 
produto; logo, prolongando a qualidade original do produto, este se mostrará viável comercialmente por um número maior de dias.

No segundo dia de armazenamento, observaramse leves rachaduras nas brácteas de hastes armazenadas a $13^{\circ} \mathrm{C}$ (figura 1), porém, como as inflorescências apresentavam coloração e turgescência características nas brácteas, as hastes florais continuaram a ser analisadas. Esse dano observado nas brácteas merece posteriores investigações, para desvendar se as rachaduras foram ocasionadas pela baixa temperatura ou se é resultado de alguma outra fonte de estresse.

A análise de variância para as notas subjetivas referentes à variável qualidade das hastes florais não apresentou diferença significativa entre os fatores isolados, nem entre suas interações. Conforme observa-se na figura 2, as hastes apresentaram, segundo as notas atribuídas, qualidade comercial após o $10^{\circ}$ dia após a colheita.

Quanto à variação da massa fresca não houve interação significativa entre os fatores, porém analisandoos individualmente a análise de variância apresentou diferença significativa tanto no fator temperatura quanto no fator solução conservante.

De acordo com AWAD (1993), a velocidade das relações metabólicas são diretamente proporcionais à temperatura, logo as hastes florais armazenadas a $13^{\circ} \mathrm{C}$ tendem a expressar menor perda de massa fresca em relação às armazenadas em ambiente com temperatura mais elevada. Foi o que se verificou neste experimento, em que as hastes florais armazenadas em temperatura mais elevada apresentavam perda percentual de massa fresca superior às expostas a $13^{\circ} \mathrm{C}$ ( $\mathrm{f}$ igura 03 ).

Após realizar o desdobramento das médias de percentual de massa fresca ao longo do tempo para o fator temperatura não houve diferença significativa até o quarto dia de avaliação. A partir do sexto dia, porém, o comportamento da manutenção da massa fresca observada nas hastes florais armazenadas à temperatura de $13^{\circ} \mathrm{C}$ tornou-se evidente, o que o diferenciou do outro tratamento físico ao nível de 5\% de significância.

A aplicação exógena de produtos cuja composição abrange substâncias bactericidas, antioxidantes, açúcares, dentre os quais se destaca a sacarose, que apresenta papel importante em diminuir a produção e sensibilidade ao etileno, supressão de substrato para respiração, manutenção de balanço hídrico adequado (PUN e ICHIMURA, 2003). Esses benefícios proporcionados pela sacarose podem ser refletidos no prolongamento da vida pós-colheita de flores de corte, como observado por WEERTS (2002) com a aplicação por $24 \mathrm{~h}$ de solução de sacarose $20 \%$ em Dianthus caryophyllus L. e por CAVALCANTE et al. (2005), em testes de concentrações de sacarose em armazenamento de hastes florais de Zingiber spectabile Griff. por 24 horas, constatando efeito positivo na manutenção da qualidade quando submetidas à concentração de $10 \%$.

Após realizar o desdobramento das médias de percentual de massa fresca ao longo do tempo para o fator solução, observou-se que as hastes florais tratadas com água e com solução conservante comercial não diferiram entre si até o sexto dia de armazenamento. A partir do oitavo dia, houve diferença significativa entre os tratamentos: as hastes florais condicionadas em solução com produto comercial apresentaram maior percentual de massa fresca que as armazenadas em água, apresentando, assim, menor perda nessa variável durante o período avaliado (figura 4).

Descartaram-se as hastes quando apresentaram nota média superior a 3 pela escala de nota subjetiva utilizada neste experimento. No $16^{\circ}$ dia após o início das avaliações, todos os tratamentos foram descartados, mostrando concordância com o resultado obtido por ALMEIDA et al. (2002) que, testando o efeito de 1metilciclopropeno em hastes florais de Zingiber spectabile armazenadas a $15^{\circ} \mathrm{C}$ sob hidratação, constatou no tratamento-controle vida útil de 15 dias após a colheita.

\section{CONCLUSÕES}

O tratamento em solução conservante comercial não proporcionou incremento na manutenção da qualidade visual das hastes florais de Zingiber spectabile Griff.

Tanto as soluções de armazenamento como as temperaturas testadas neste experimento agiram independentes na variação do percentual de massa fresca.

A solução conservante comercial e a temperatura de $13^{\circ} \mathrm{C}$ mostraram-se eficientes na redução da perda de massa fresca das hastes florais.

\section{REFERÊNCIAS}

ALMEIDA, A.S., ALVES, R.E., PAIVA, W.O., LIMA, M.C., ALMEIDA, J.B.S.A. Qualidade e conservação de sorvetões (Zingiber spectabilis) tratado em pós-colheita com 1-metilciclopropeno (1-MCP). Interamerican Society Tropical Horticulture. V. 46, p. 110-111, 2002.

AWAD, M. Fisiologia pós-colheita de frutos. 1.ed. São Paulo, SP: Nobel, 1993. 113p.

CASTRO, C.E.F. de. Cadeia produtiva de flores e plantas ornamentais. Revista Brasileira de Horticultura Ornamental, Campinas, v.4, n.1/2, p. 1-46, 1998.

CASTRO, C.E.F. de. Helicônias como flores de corte: adequação de espécies e tecnologia pós-colheita. Piracicaba - SP: Universidade de São Paulo, 1993. 191 p. Tese de Doutorado (Fitotecnia).

CAVALCANTE, R.A.; MOSCA, J.L.; MACIEL, V.T.; PAIVA, W.O. Efeito de solução pulsing com sacarose na manutenção da qualidade pós-colheita de Zingiber spectabile Griff. In: CONGRESSO BRASILEIRO DE OLERICULTURA, 45.; CONGRESSO BRASILEIRO DE FLORICULTURA E PLANTAS ORNAMENTAIS, 15.; CONGRESSO BRASILIRO DE CULTURA DE TECIDOS DE PLANTAS, 2., 2005, Fortaleza. Resumos. Fortaleza: Revista da Associação Brasileira de Horticultura, 2005, v.23, n.2, p. 564.

CHITARRA, M.I.F.; CHITARRA, A.B. Pós-colheita de frutos e hortaliças: Fisiologia e manuseio. ESAL/FAEPE, Lavras, 1990, 293p. 
KIYUNA, I.; ÂNGELO, J.A.; COELHO, P.J. Flores: desempenho do comércio exterior em 2007. Análise e indicadores do agronegócio. Instituto de Economia Agrí́cola, v.3, n.1, janeiro de 2008.

LAMAS, A.M. Flores: Produção, pós-colheita e mercado. Instituto Frutal, Curso Técnico. Fortaleza, Ceará - 2004. 109p.

LAMAS, A.M. Floricultura tropical: técnicas de cultivo. Recife, PE: SEBRAE, 2002. 84p.

LOPES, S.L.; GRAZIANO, T.T. A produção e a comercialização de Heliconia spp. no Estado de São Paulo. Revista Brasileira de Horticultura Ornamental, Campinas, v.7, n.2, p. 81-88, 2001.

MORAES, P.J. de. Efeito da refrigeração e do condicionamento em sacarose sobre a conservação póscolheita de flores de Strelitzia reginae Ait. Viçosa - MG: Universidade Federal de Viçosa, 1999. 48 p. Dissertação de Mestrado.
OLIVEIRA, M.J.G. de Tecnologia pós-colheita de Heliconia spp. Campinas - SP: Universidade Estadual de Campinas, 1996. 111 p. Dissertação de Mestrado (PréProcessamento de Produtos Agrícolas).

PUN, U.; ICHIMURA, K. Role of sugars in senescence and biosynthesis of ethylene in cut flowers. Japanese Society for the Promotion of Science. Tokyo, vol.37, n.1, p. 219-224, 2003.

TAGLIACOZZO, G.M.D.; FINGER, L.F.; BARBOSA, J.G. Fisiologia pós-colheita de flores de corte. Revista Brasileira de Horticultura Ornamental. Campinas, v.11, n.2, p. 89-99, 2005.

WEERTS, J.A. The effect of sucrose-pulsing on cut carnation and freesia flowers. Faculty of Science at the Rand Afrikkans University, 2002. 102 p. Dissertation for the degree Magister Scientiae in Botany.

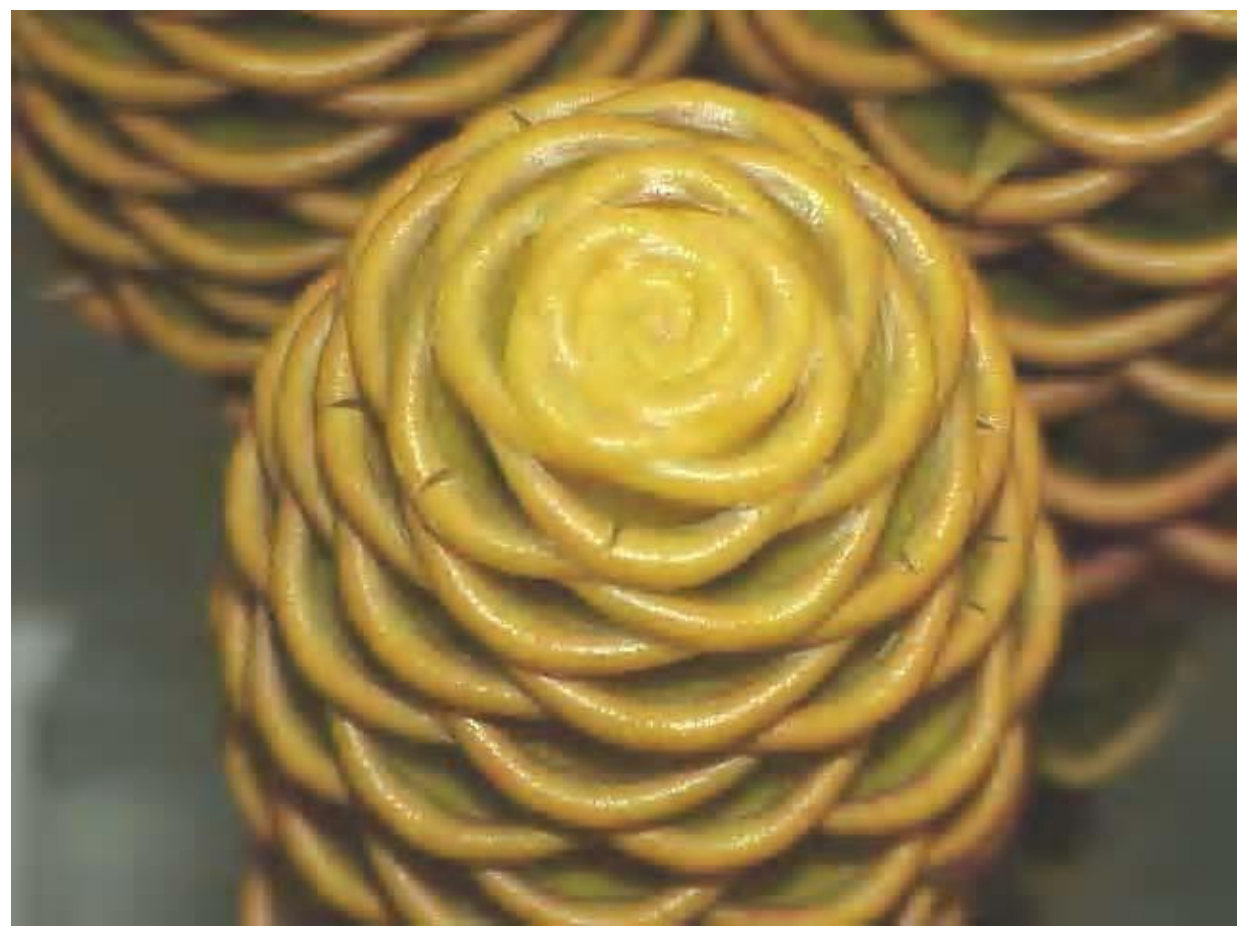

Figura 1. Rachaduras observadas nas brácteas das inflorescências armazenadas à temperatura de $13^{\circ} \mathrm{C}$ no segundo dia de armazenamento.

Figure 1. Cracks observed in the bracts of the inflorescences stored to the temperature of $13^{\circ} \mathrm{C}$ in as the day of storage. 
- $13^{\circ} \mathrm{C}$ - Água

$13^{\circ} \mathrm{C}$ - Flower ${ }^{\circledR}$

$\triangle 15^{\circ} \mathrm{C}$ - Água

$\times 15^{\circ} \mathrm{C}-$ Flower $^{\circledR}$

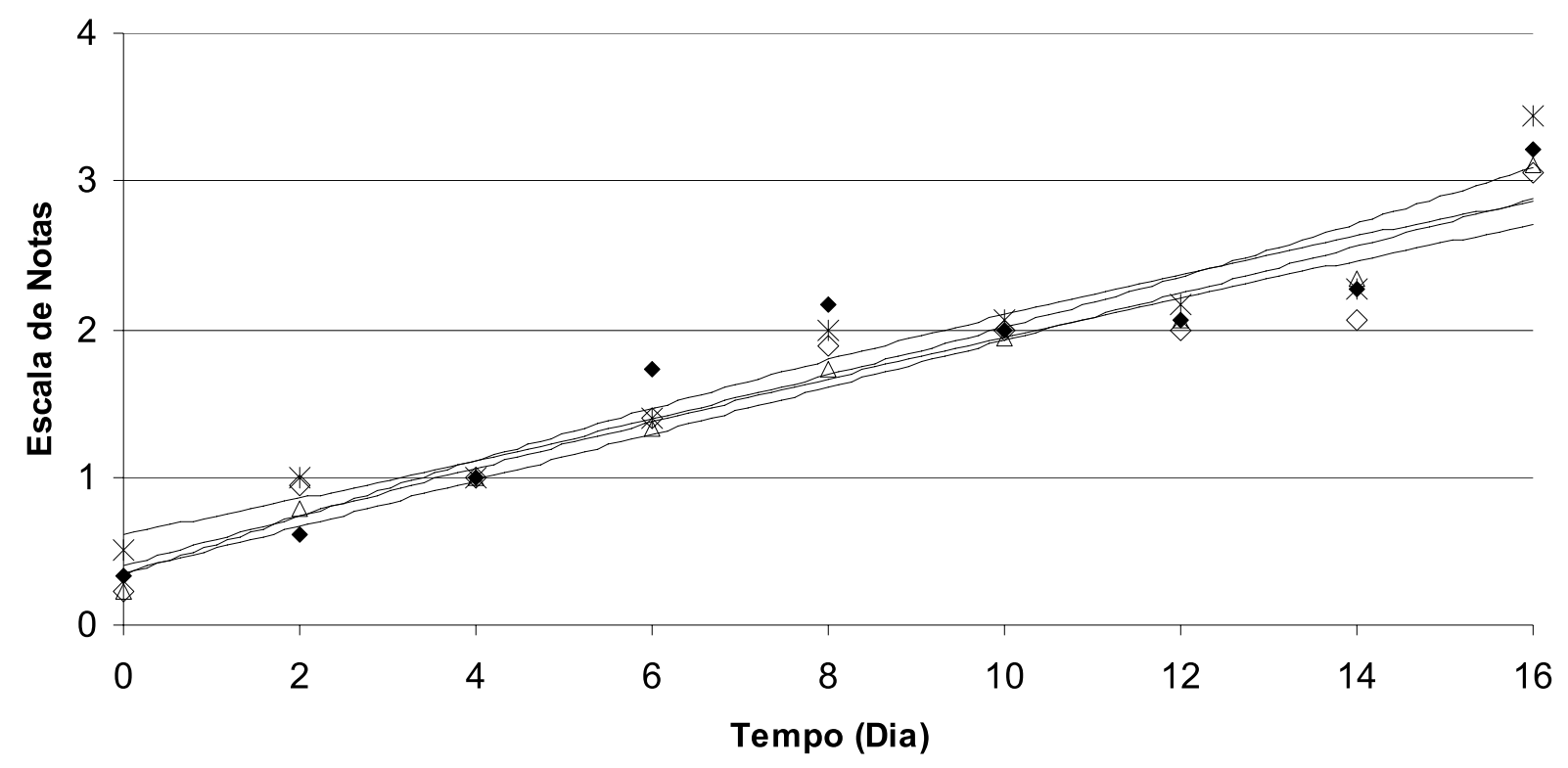

\begin{tabular}{lcc}
\hline \multicolumn{1}{c}{ Tratamento } & \multicolumn{1}{c}{ Equação } & $\mathbf{R}^{2}$ \\
\hline $13^{\circ} \mathrm{C}-$ Água & $\mathrm{Y}=-0,0031 \mathrm{x} 2+0,2067 \mathrm{x}+0,333$ & 0,9094 \\
$13^{\circ} \mathrm{C}-$ Flower ${ }^{\circledR}$ & $\mathrm{Y}=-0,0018 \mathrm{x} 2+0,1726 \mathrm{x}+0,3987$ & 0,9142 \\
$15^{\circ} \mathrm{C}-$ Água & $\mathrm{Y}=0,0001 \times 2+0,1557 \mathrm{x}+0,3532$ & 0,97 \\
$15^{\circ} \mathrm{C}-$ Flower & $\mathrm{Y}=0,0026 \times 2+0,114 \mathrm{x}+0,6145$ & 0,922 \\
\hline
\end{tabular}

Figura 2. Alteração da qualidade no período pós-colheita de hastes florais, segundo escala subjetiva de notas, condicionadas a quatro tratamentos, sendo: $13^{\circ} \mathrm{C}-$ Água (armazenamento à temperatura de $13^{\circ} \mathrm{C}$ em recipientes com água); $13^{\circ} \mathrm{C}-$ Flower ${ }^{\circledR}$ (armazenamento à temperatura de $13^{\circ} \mathrm{C}$ em recipientes com solução comercial Flower ${ }^{\circledR}$ na concentração $30 \mathrm{~mL} / 1 \mathrm{~L}$ de água); $15^{\circ} \mathrm{C}$ - Água (armazenamento à temperatura de $15^{\circ} \mathrm{C}$ em recipientes com água), $15^{\circ} \mathrm{C}-$ Flower ${ }^{\circledR}$ (armazenamento à temperatura de $15^{\circ} \mathrm{C}$ em recipientes com solução comercial Flower ${ }^{\circledR}$ na concentração $30 \mathrm{~mL} / 1 \mathrm{~L}$ de água). 


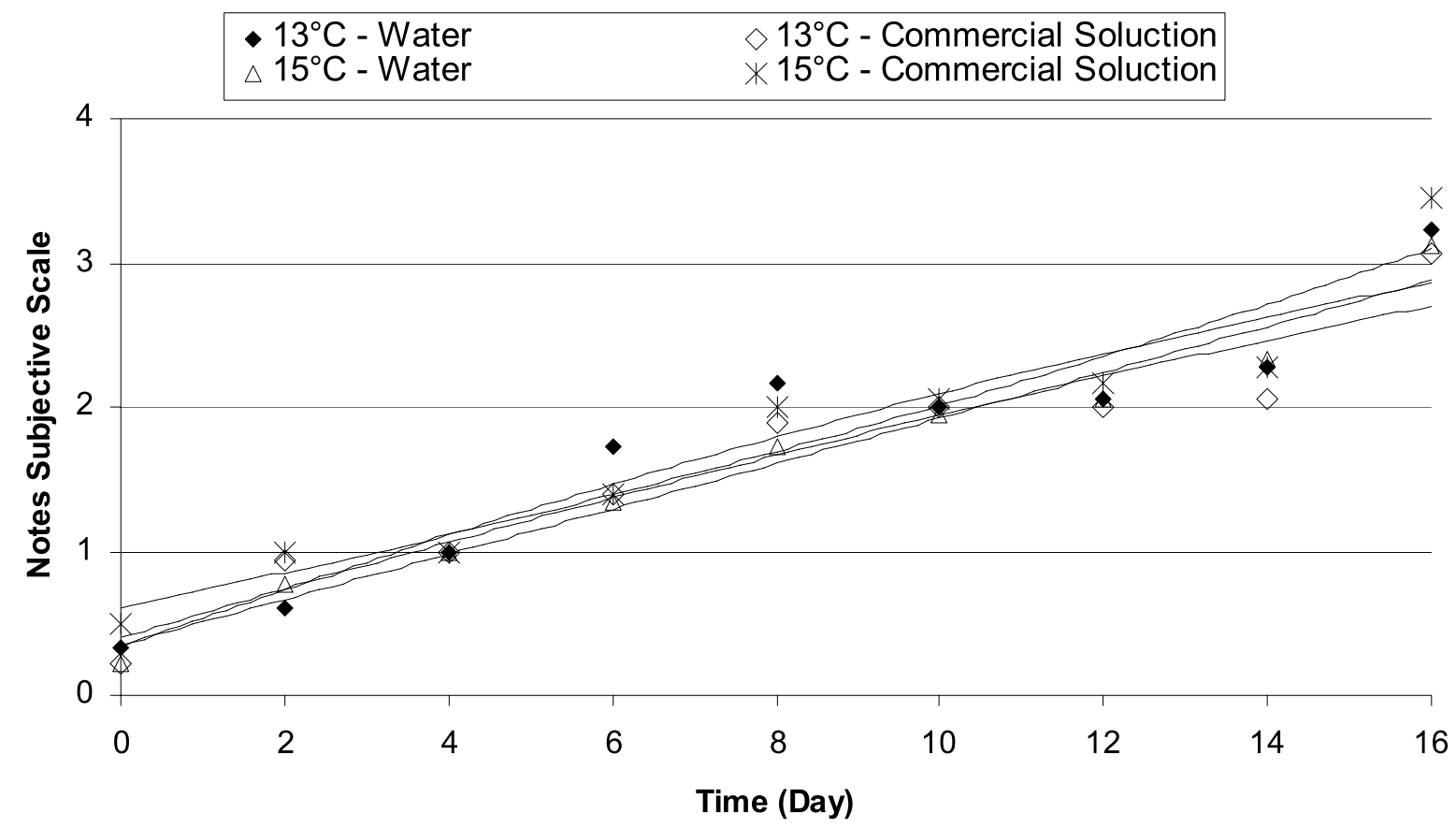

\begin{tabular}{lcc}
\hline \multicolumn{1}{c}{ Treatment } & Equation & $\mathbf{R}^{2}$ \\
\hline $13^{\circ} \mathrm{C}-$ Water & $\mathrm{Y}=-0,0031 \mathrm{x} 2+0,2067 \mathrm{x}+0,333$ & 0,9094 \\
$13^{\circ} \mathrm{C}-$ Commercial solution & $\mathrm{Y}=-0,0018 \mathrm{x} 2+0,1726 \mathrm{x}+0,3987$ & 0,9142 \\
$15^{\circ} \mathrm{C}-$ Água & $\mathrm{Y}=0,0001 \times 2+0,1557 \mathrm{x}+0,3532$ & 0,97 \\
$15^{\circ} \mathrm{C}-$ Commercial solution & $\mathrm{Y}=0,0026 \times 2+0,114 \mathrm{x}+0,6145$ & 0,922 \\
\hline
\end{tabular}

Figure 2. Alteration of the quality in the postharvest period of floral steam according to notes subjective scale, conditional the four treatments, being: $13^{\circ} \mathrm{C}$ - Water (storage to the temperature of $13^{\circ} \mathrm{C}$ in containers with water); $13^{\circ} \mathrm{C}$ - Flower ${ }^{\circledR}$ (storage to the temperature of $13^{\circ} \mathrm{C}$ in containers with commercial solution Flower ${ }^{\circledR}$ in the concentration $30 \mathrm{~mL} / 1 \mathrm{~L}$ of water); $15^{\circ} \mathrm{C}$ - Water (storage to the temperature of $15^{\circ} \mathrm{C}$ in containers with water); $15^{\circ} \mathrm{C}$ - Flower ${ }^{\circledR}$ (storage to the temperature of $15^{\circ} \mathrm{C}$ in containers with commercial solution Flower ${ }^{\circledR}$ in the concentration $30 \mathrm{~mL} / 1 \mathrm{~L}$ of water). 


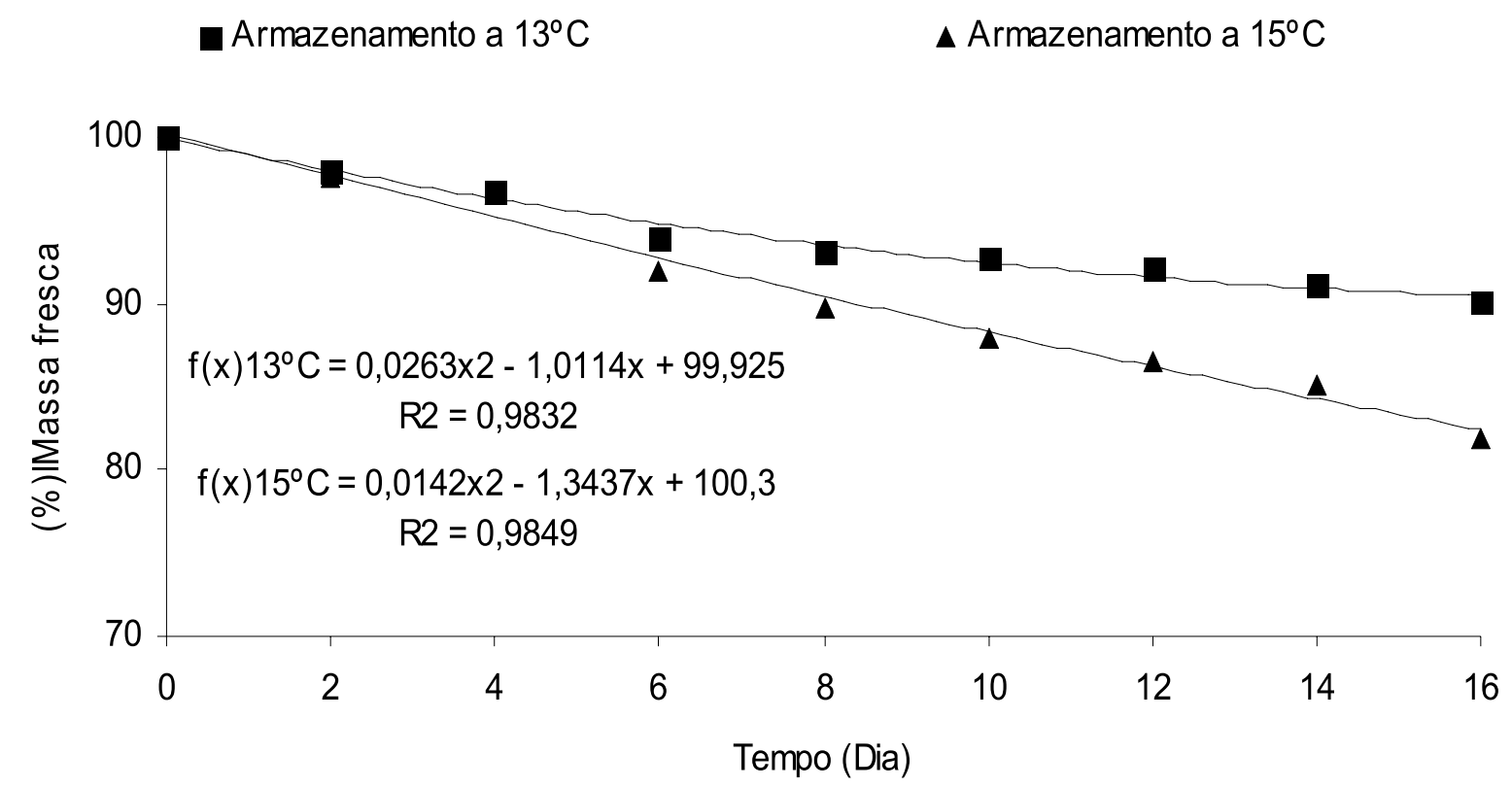

Figura 3. Variação do percentual da massa fresca das hastes florais em relação ao primeiro dia de avaliação e ao parâmetro armazenamento refrigerado (temperatura $13^{\circ} \mathrm{C}$ ou $15^{\circ} \mathrm{C}$ ), isolado durante o período de armazenamento.

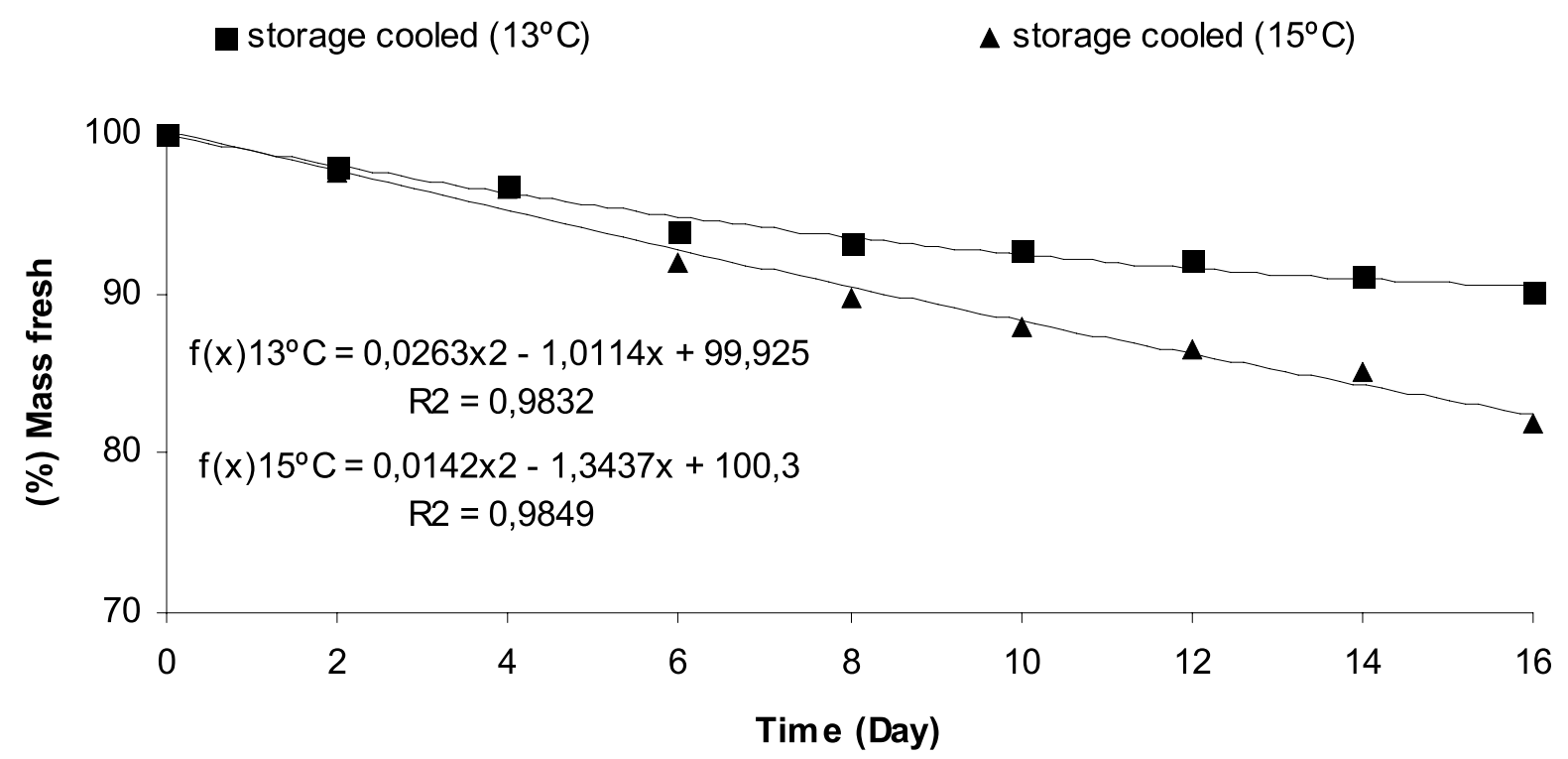

Figure 3. Variation of the fresh mass percentage of floral steam in relation to the first day of evaluation and the parameter storage cooled (temperature $13^{\circ} \mathrm{C}$ or $15^{\circ} \mathrm{C}$ ) isolated during the period of storage. 
Água $\square$ Solução comercial

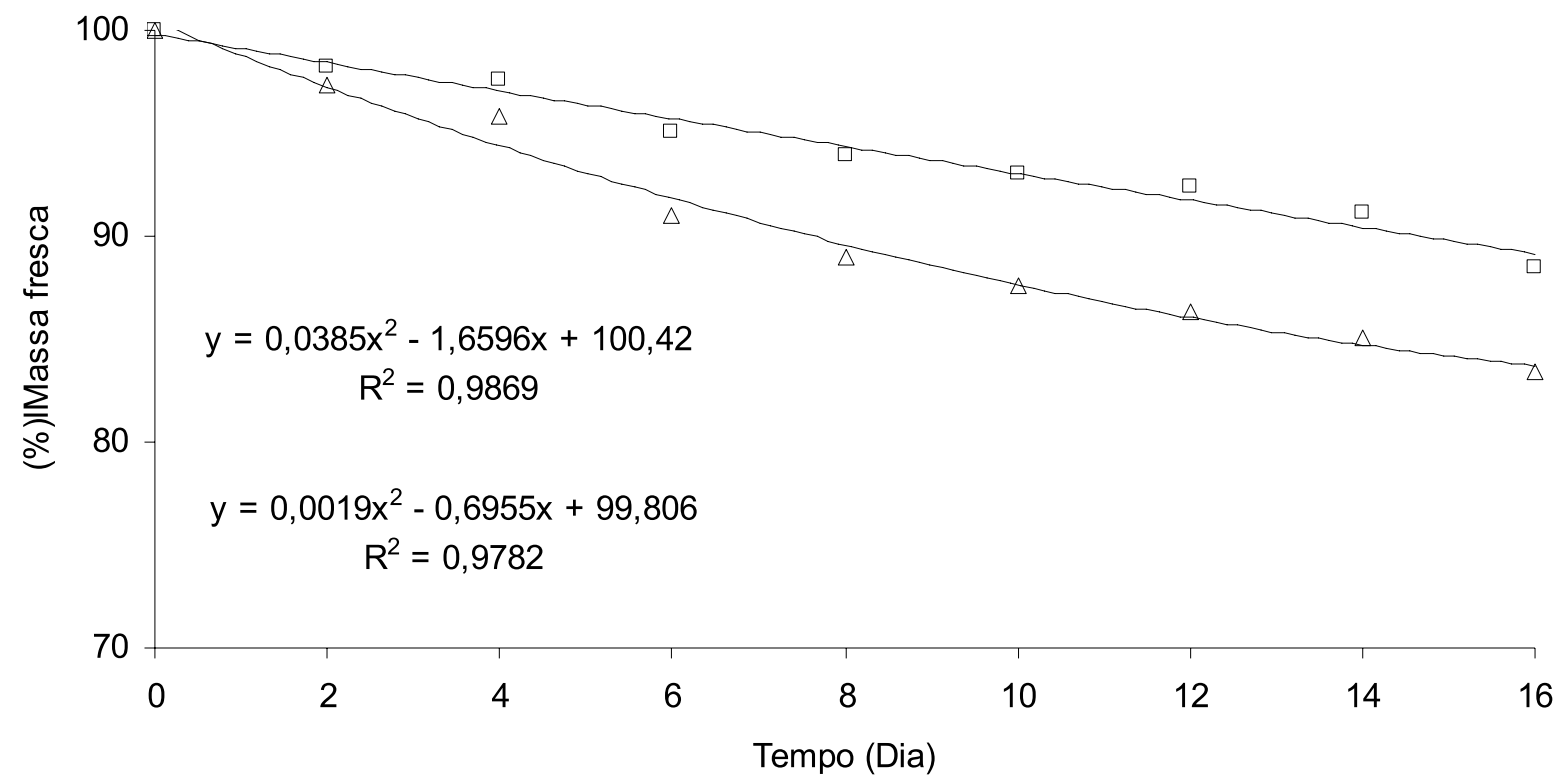

Figura 4. Variação do percentual da massa fresca de hastes florais em relação ao primeiro dia de avaliação e ao parâmetro solução conservante (armazenamento em água ou em solução conservante comercial), isolado durante o período de armazenamento.

\section{Water $\square$ Commercial solutionl}

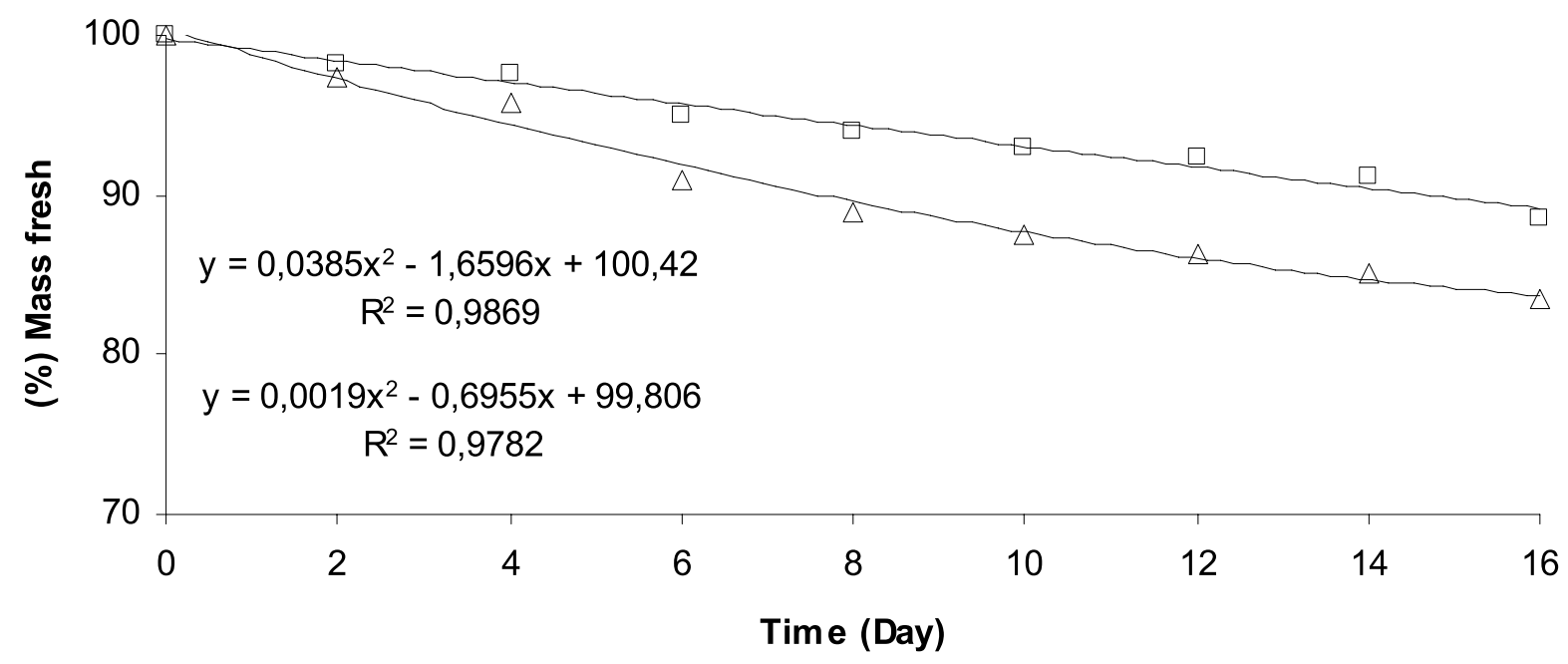

Figure 4. Variation of the fresh mass percentage of floral steam in relation to the first day of evaluation and the parameter maintenance solutions (storage in water or in commercial maintenance solution) isolated during the period of storage. 